Olga Garcia Falceto ${ }^{1}$

CARMEN LUISA FERNANDES ${ }^{2}$

SUZI ROSELI KERBER ${ }^{3}$

\section{Alerta sobre a depressão pós-parto paterna}

\section{Alert on paternal postpartum depression}

Este editorial busca alertar sobre a importância de um quadro bastante negligenciado na clínica médica: os transtornos psiquiátricos pós-parto paternos, especialmente, a depressão. Fazemos uma breve revisão de publicações recentes, com ênfase nas de nosso grupo de pesquisa. Esse alerta é ainda mais importante para os gineco-obstetras, que concentram sua maior atenção sobre as mulheres. Nossos estudos dão suporte às recomendações atuais de incluir o pai nas consultas de pré-natal com o fim de estimular a formação de vínculos familiares saudáveis ${ }^{1}$.

A depressão pós-parto (DPP) é tipicamente tratada como um problema exclusivo das mulheres e que ocorre, ao longo do primeiro ano de vida do filho, em 10 a $15 \%$ delas. Entretanto, os pais também passam por mudanças significativas após o nascimento da criança. Essas, em grande parte, se assemelham às que ocorrem com as mães. Ambos vivenciam transformações importantes no seu sentido de identidade pessoal, papéis familiares e sociais. Mudam, em especial, as relações interpessoais do casal e também as rotinas diárias ${ }^{2,3}$, principalmente do sono ${ }^{4}$.

Os estudos indicam que transtornos psiquiátricos pós-parto paternos apresentam prevalência significativa (no Brasil variam entre $11,9^{3}$ e 25,4\% ${ }^{5}$ ) e impactam diretamente no apoio que o pai dá à mãe e ao bebê durante o primeiro ano pós-parto ${ }^{6}$ Nosso grupo realiza uma pesquisa longitudinal do desenvolvimento de famílias. Em sua primeira etapa, entrevistou, em suas casas, quatro meses após o nascimento, todas as famílias que tiveram filho em hospital público no ano de 1999, em um bairro de Porto Alegre. Encontramos uma frequência de suspeita de transtorno mental (medida pela escala SRQ-20) de 34,5\% nas mulheres e $25,4 \%$ nos homens 5 .

Ao contrário da grande quantidade de estudos publicados sobre os fatores ligados à depressão pós-parto materna (DPPM), pouco se sabe sobre o desenvolvimento de tais sintomas nos pais ${ }^{2,3,7}$. Estudos recentes relatam que teriam relação com diversos fatores biológicos (principalmente uma desregulação hormonal que ocorreria nos homens entre os últimos meses da gravidez da parceira e o primeiro ano do período pós-parto) e ambientais, como complicações da relação conjugal e dificuldade de formar uma ligação afetiva com o filho ${ }^{6}$.

Não é infrequente que o homem demonstre mais dificuldade na formação do vínculo afetivo com o filho, comparado com a mulher, que tipicamente é socializada de forma a aprender a lidar com crianças e, além disso, apresenta taxas elevadas de ocitocina, hormônio reconhecidamente associado com a formação do vínculo mãe-criança. Há, também, a falta

Correspondência Olga Garcia Falceto Rua Ramiro Barcelos, 2350 (EP: $90035-003$ Porto Alegre (RS), Brasil

Recebido 02/04/2012

Trabalho realizado na Universidade Federal do Rio Grande do Sul - UFRGS - Porto Alegre (RS), Brasil.

' Departamento de Psiquiatria e Medicina Legal da Faculdade de Medicina da Universidade Federal do Rio Grande do Sul - UFRGS Porto Alegre (RS), Brasil.

${ }^{2}$ Grupo Hospitalar Conceição - Porto Alegre (RS), Brasil.

${ }^{3}$ Psiquiatra da Infância e Adolescência - Porto Alegre (RS), Brasil.

Conflito de interesses: não há

Aceito com modificaçōes 
de um modelo a seguir, já que os homens acabam por não passar aos filhos conhecimentos sobre o que fazer para ser um bom pai. Esse fato está associado com uma maior ansiedade frente à difícil tarefa de cuidar de um recém-nascido. No âmbito conjugal, há potenciais complicações, como o ciúme pela dominância do papel materno na nova relação familiar e a relativa exclusão do homem da dupla mãe-filho. É também frequente que haja uma diminuição temporária do interesse sexual da parceira. $\mathrm{O}$ estresse da paternidade pode ser ainda complicado devido às diferenças nas tarefas destinadas a cada gênero, com a ênfase no papel do homem como provedor. No período pós-parto, aumentam as preocupações financeiras e, consequentemente, a dedicação do homem ao trabalho, o que pode diminuir ainda mais o tempo destinado ao relacionamento pai-filho. $\mathrm{O}$ medo de falhar nas tarefas de provedor, apoiador emocional e parceiro romântico está relacionado ao estresse psicológico paterno, levando, em muitos casos, ao desenvolvimento de sintomas depressivos. Também pode ocorrer que a criança acabe contribuindo com o problema: a falta de experiência e o menor tempo de convivência com a criança (comparado com a mãe) podem tornar suas interações menos interessantes para o filho, tendendo esse a dar-lhe um menor número de retribuições (como sorrisos e vocalizações), aumentando o estresse paterno ao longo do primeiro ano pós-parto 5 .

Um ponto importante a ser destacado é a forte associação entre a DPP paterna e a materna ${ }^{2,3,5}$. Nosso grupo identificou essa correlação em $70 \%$ dos casos de transtorno emocional materno ${ }^{4}$. Tanto a prevalência, quanto a severidade da DPP paterna aumentam de acordo com a severidade da depressão de sua parceira ${ }^{3}$. Ainda é obscura, porém, qual a relação entre a DPP na mulher e no homem ${ }^{6,7}$, ainda que, estudando a mãe, nosso grupo tenha demonstrado associação significativa especificamente com a qualidade da relação conjugal ${ }^{7}$. A sinergia entre os sintomas depressivos da mãe e do pai pode se dar pelo estado psicológico de um dos parceiros, que acaba influenciando o do outro, seja diretamente por questões afetivas, ou indiretamente pelas consequências das rotinas diárias serem alteradas pelos problemas vivenciados. Como o homem geralmente conta prioritariamente com o apoio emocional da companheira, quando sente uma diminuição de sua atenção, seja pela alteração de seu humor, excesso de tarefas, falta de repouso e aumento dos conflitos do casal, passa a desenvolver uma atitude mais introspectiva, afasta-se da companheira e tem dificuldades no desempenho do papel paterno e em outras áreas da vida, podendo desenvolver sintomas de depressão $0^{5,7}$.

A alta prevalência de DPP paterna tem grandes implicações também sobre o bem-estar da criança. Mães e pais com DPP demonstram menos evidências de apego emocional a seus bebês e capacidade de estimular o seu desenvolvimento. Se ambos os pais experimentarem sintomas depressivos durante o período pós-parto, a interação entre a depressão da mãe e do pai pode acarretar um risco ainda maior para o desenvolvimento da criança ${ }^{2}$. Além disso, a DPP, quando persistente, pode favorecer a ocorrência de situações de negligência e abuso infantil ${ }^{6}$.

Tradicionalmente, na cultura brasileira, espera-se do pai apenas que seja provedor e ofereça apoio a sua parceira nos cuidados com o bebê, os quais seriam da esfera de responsabilidades da mãe (junto com as tarefas domésticas). Mudanças socioculturais, como a entrada da mulher no mercado de trabalho e o desenvolvimento de papéis mais equitativos para mulheres e homens na família, vêm modificando essa situação. Estudo de nosso grupo evidenciou que 33\% dos pais que coabitavam com a mãe do bebê de 4 meses não participavam ativamente dos cuidados desse 5 . O estudo dos fatores demográficos e relacionais demonstrou associação significativa entre o envolvimento do pai nos cuidados do lactente apenas com a má qualidade da relação conjugal e com o fato da esposa não trabalhar fora do lar, o que amplia o que foi discutido. Não houve evidência de menor envolvimento se o pai estava deprimido, o que, a nosso ver, demonstra a importância do papel de pai (preservando-o mesmo na vigência de problemas emocionais) no ciclo de vida do homem e a necessidade de mais pesquisa sobre o assunto ${ }^{7}$.

Para facilitar o processo de transição do homem de filho para pai, diferentes tipos de apoio fazem-se necessários. Já foi dito que o apoio mais efetivo para os homens geralmente vem de suas parceiras, mas programas educacionais na comunidade também podem ser importante forma de suporte, já que é comum a falta de uma rede social compreensiva e apoiadora para os novos pais. Pouco se estudou também o papel da família extensa nesse processo, levando em conta que há uma necessidade de mudança social para apoiar o 'novo' pai. Por exemplo, programas de apoio na área da saúde para evitar o desenvolvimento da DPP são tradicionalmente voltados apenas para as mães. Quando são voltados para o casal, os homens tendem a não participar (assim como ocorre na maioria das ações de saúde). Isso se deve, em grande parte, à falta de informação dos homens sobre a necessidade desse apoio. Há relatos na literatura de programas em que, quando o pai era informado da importância e convidado a participar diretamente, e não por meio da esposa, o índice de aceitação era maior ${ }^{7}$.

Até o momento, a DPP paterna só foi estudada por um pequeno número de pesquisadores ${ }^{7-9} \mathrm{e}$, predominantemente, em países desenvolvidos. Está na hora de termos mais estudos brasileiros que ajudarão a responder muitas questões, inclusive achados contraditórios sobre o impacto do transtorno mental na família. Sabe-se que a relação mãe-filho saudável está associada com o bom desenvolvimento físico e mental da criança, mas pouco se sabe sobre essa associação 
com a relação pai-filho. Em nossa coorte, identificamos que já aos 4 meses havia problemas persistentes na relação de 9,5\% das duplas mãe-filho e de $12 \%$ das duplas pai-filho. Para a mãe, esse achado estava significativamente relacionado com transtorno mental do pai, rede social pobre e também interrupção precoce do aleitamento (mas não com presença de transtorno mental materno). Para o pai, estava associado com relação conjugal problemática e baixo peso do bebê ao nascer, mas não com presença de transtorno mental nele ${ }^{10}$. Todos esses fatores associados são passíveis de intervenção de profissionais da saúde com potencial de boa resolutividade, em especial o tratamento dos transtornos mentais e das relações conjugais problemáticas ${ }^{11,12}$. É sabido que há consequências em longo prazo para o filho quando a relação pai-filho é conflituosa ou distante. Entre outras, pode-se citar a maior prevalência de transtornos de comportamento e maior possibilidade de envolvimento com drogas na adolescência ${ }^{13}$. Portanto, uma mudança na forma com que os serviços de saúde prestam assistência ao início da formação da família e da construção do papel de pai poderá ter grande impacto para melhorar a vida dos indivíduos, famílias e comunidades.

Esperamos ter demonstrado que é necessária uma maior conscientização dos profissionais da área da saúde sobre os transtornos mentais do pai no pós-parto, devido a sua relevante prevalência, assim como sua associação com outros problemas. Deve-se buscar, desde o período pré-natal, uma integração entre profissionais de diversas especialidades (gineco-obstetras, pediatras, médicos de família e comunidade, clínicos, psiquiatras, psicólogos) para o acompanhamento não só da dupla mãe-criança, mas sim do casal e seu filho. Recomendamos, portanto, que o pai seja incluído no maior número de consultas peri-natais possível.

\section{Agradecimento}

À Vítor Rocco Torrez - Graduando em Medicina na Universidade Federal do Rio Grande do Sul.

\section{Referências}

1. Buchabqui JA, Abeche AM, Nickel C. Assistência pré-natal. In: Freitas F, Martins-Costa SH, Ramos JGL, Magalhães JA, organizadores. Rotinas em obstetrícia. 6a ed. Porto Alegre: Artmed; 2011. p. 23-45.

2. Goodman JH. Paternal postpartum depression, its relationship to maternal postpartum depression, and implications for family health. J Adv Nurs. 2004;45(1):26-35.

3. Pinheiro RT, Magalhães PV, Horta BL, Pinheiro KA, da Silva RA, Pinto RH. Is paternal postpartum depression associated with maternal postpartum depression? Population-based study in Brazil. Acta Psychiatr Scand. 2006; 1 13(3):230-2.

4. Falceto OG, Giugliani ER, Fernandes CL. Influence of parental mental health on early termination of breast-feeding: a case-control study. J Am Board Fam Pract. 2004;17(3):173-83.

5. Kerber SR, Falceto OG, Fernandes CLC. Problemas conjugais e outros fatores associados a transtornos psiquiátricos do pós-parto. Rev Bras Ginecol Obstet. 2011;33(6):281-7.

6. Kim P, Swain JE. Sad dads: paternal postpartum depression. Psychiatry (Edgmont). 2007;4(2):35-47.

7. Morgan M, Matthey S, Barnett B, Richardson C. A group programme for postnatally distressed women and their partners. J Adv Nurs. 1997;26(5):913-20.

8. Areias ME, Kumar R, Barros H, Figueiredo E. Comparative incidence of depression in women and men, during pregnancy and after childbirth. Validation of the Edinburgh Postnatal Depression Scale in Portuguese mothers. Br J Psychiatry. 1996;169(1):30-5.

9. Matthey S, Barnett B. Parent-infant classes in the early postpartum period: need and participation by fathers and mothers. Infant Ment Health J. 1999;20(3):278-90.

10. Falceto OG, Giugliani ERJ, Fernandes CLC. Problematic parent-infant relationships in two-parent families: prevalence and risk factors in a Brazilian neighborhood. Rev Psiquiatr Rio Gd Sul. No prelo 2011.

11. Hollist CS, Miller RB, Falceto OG, Fernandes CL. Marital satisfaction and depression: a replication of the Marital Discord Model in a Latino sample. Fam Process. 2007;46(4):485-98.

12. Waldemar JOC. Terapia de casal. In: Cordioli AV, organizador. Psicoterapias: abordagens atuais. 3a ed. Porto Alegre: Artmed; 2007. p. $246-62$.

13. Ramos SP. What can we learn from psychoanalysis and prospective studies about chemically dependent patients? Int J Psychoanal. 2004;85(Pt 2): 467-87. 